\title{
Comparative Biodrying Performance of Municipal Solid Waste in the Reactor under Greenhouse and Non-greenhouse Conditions
}

\author{
Katitep Ngamket, Komsilp Wangyao, Sirintornthep Towprayoon* \\ ${ }^{1}$ The Joint Graduate School of Energy and Environment (JGSEE), King Mongkut's University of Technology Thonburi, Center of Excellence on Energy \\ Technology and Environment (CEE), PERDO, Ministry of Higher Education, Science, Research and Innovation, Bangkok
}

Received: 01/09/2020

Accepted: 05/11/2020

Published: 20/03/2021

\begin{abstract}
The high moisture content of municipal solid waste yields a lower energy content of solid fuel that affects the thermal conversion efficiency. Biodrying is an alternative drying method using bio-heat generated by microbial metabolism to reduce the moisture content of municipal solid waste. This research was conducted in three pilot-scale biodrying reactors, two under greenhouse conditions compared with one conventional non-greenhouse condition. Two bunkers with greenhouse cladding were connected with aerators, and airflow rates were set at 0.4 and $0.6 \mathrm{~m}^{3} /\left(\mathrm{kg}_{\text {waste }}\right.$ day), respectively. Meanwhile, a passive aeration method was applied to the non-greenhouse bunker. This study aims to investigate the effect of the greenhouse condition on the biodrying process and assess the performance of the drying process through different operating conditions. The result shows that the greenhouse mainly affects the air temperature rise in the reactor. The aeration rate is positively correlated with weight reduction $(\mathrm{r}=0.93)$. At $0.6 \mathrm{~m}^{3} /\left(\mathrm{kg}_{\text {waste }} \cdot\right.$ day) airflow rate, the treatment can reach a moisture content less than $30 \%$ on average within ten days, while at $0.4 \mathrm{~m}^{3} /\left(\mathrm{kg}_{\text {waste }} \cdot\right.$ day) airflow rate, it takes 15 days to reduce the moisture content to less than $30 \%$. Biodrying under the greenhouse condition with active aeration potentially achieves desirable moisture content reduction and heating value increase more efficiently than the common biodrying. However, the airflow rate is a crucial factor in determining the suitable drying time in biodrying under the greenhouse condition.
\end{abstract}

Keywords: Biodrying, Greenhouse, Municipal Solid Waste, Refuse Derived-Fuel, Solar Radiation

\section{Introduction}

The Thai government has been developing the Bio-CircularGreen Economy (BCG) model since 2019. This model focuses on socio-economic and environmental improvements to reach sustainable development goals. The linear economy of the takemake-use-dispose concept is being reformed into a circular economy. The development of community-based biomass power plants using refuse-derived fuel (RDF), which is obtained from processed municipal solid waste (MSW), is aligned with the BCG model. Additionally, alternative energy will amount to $30 \%$ of all energy consumption in this country by 2036 [1]. The challenge of RDF production is that MSW has a high moisture content (MC) and organic fraction. The MSW characteristics cause low energy content in RDF, leading to low energy gain from the thermal conversion process. Therefore, it is necessary to improve the MSW properties for the efficiency of energy production by reducing the $\mathrm{MC}$ while increasing the heating value (HV), by adding a drying process to MSW preparation before the heat conversion process.
There are many available drying methods for MSW, such as thermal drying and biodrying. The benefit of thermal drying is the shorter drying period $(2.64 \pm 1.44 \mathrm{~h})$ [2]. Meanwhile, the drying time of biodrying is about $16 \pm 7$ days [2]. Nonetheless, thermal drying could have higher maintenance and operation costs for large-scale drying applications. Biodrying is an alternative drying method that uses metabolic energy from biodegradation for water evaporation in MSW or wastewater sludge.

Aeration is a critical concern for heat generation from aerobic decomposition. The various optimal airflow rate in many biodrying studies depends on initial moisture content, reactor type, and feedstock composition. A study from Shao et al. [3] conducted biodrying lysimeter measurements, using 0.34 $\mathrm{m}^{3} /\left(\mathrm{kg}_{\text {waste }} \cdot\right.$ day $)$ of airflow rate to dry MSW with initially $74 \%$ MC for 16 days resulting in 30\% MC. Research of Tom et al. [4] set $0.53 \mathrm{~m}^{3} /\left(\mathrm{kg}_{\text {waste }}\right.$ day) of airflow rate to reduce $\mathrm{MC}$ of MSW from 61.25 to $30 \%$ in approximately 33 days. In the case of Debicka et al. [5], a study in the industrial-scale biodrying reactor applied an airflow rate at $1.80-2.16 \mathrm{~m}^{3} /\left(\mathrm{kg}_{\text {waste }}\right.$ - day $)$ to reduce $\mathrm{MC}$ by $50 \%$ within one week (the final MC was less than $22 \%$ ). The

*Corresponding author: Sirintornthep Towprayoon, The Joint Graduate School of Energy and Environment (JGSEE), King Mongkut's University of Technology Thonburi (KMUTT), Bangkok, Thailand. E-mail: sirin.jgsee@gmail.com 
advantages of the biodrying method are the decreases in weight, volume, and MC of MSW. However, this method can be a costly technology for developing countries.

Biodrying under greenhouse conditions is appropriate for developing countries that have high solar radiation intensity. In Thailand, the average of daily solar radiation intensity is 17.6 $\mathrm{MJ} /\left(\mathrm{m}^{2}\right.$. day) [6]. The drying process under greenhouse conditions contributes to two main effects: 1) higher air temperature and relative humidity in the greenhouse is than the external condition and 2) an improvement in microbial growth and activity [7]. Additionally, the research of biodrying under greenhouse conditions conducted by Zaman et al. [8] showed that the biodrying process can abate $\mathrm{CO}_{2}$ emission by 13 times and can produce RDF with an $\mathrm{HV}$ up to $6,265 \mathrm{kcal} / \mathrm{kg}$. According to the meta-analysis by Tun and Juchelkova [2], most biodrying studies were conducted on a laboratory scale. Particularly in biodrying under greenhouse conditions, there is no publicised research on a pilot or industrial scale. To fill in this gap in the literature, this study aims to compare the effect of greenhouse and nongreenhouse conditions on the biodrying process on a pilot scale. The result of this novel design study can be a practical direction for the improvement and implementation of MSW biodrying under greenhouse conditions in developing countries.

\section{Materials and Method}

\subsection{Greenhouse structure and design}

Three greenhouse bunkers are located at the On-nut sewage treatment plant near the On-nut waste transfer station in Bangkok, Thailand. We designed the square bunkers to be $3.50 \mathrm{~m}$ wide, 4.35 $\mathrm{m}$ long, and $2.20 \mathrm{~m}$ high. The base for the bunkers was raised to $0.25 \mathrm{~m}$ to provide inner gutters. These internal gutters allowed for air pathways and leachate drainage. A centrifuge aerator was connected at the posterior of each greenhouse; the air was fed through 6 in $(0.15 \mathrm{~m})$ diameter pipes. The ventilation fans at the superior space inside greenhouses automatically expelled the exhausted air when the relative humidity inside the greenhouse exceeded $60 \%$. When relative humidity was less than $60 \%$, the exhausted air was drained by passive ventilation. The controller box at the rear of each greenhouse contained a data logger, humidity sensor, and switching power supply. Metal rooftops were covered by transparent acrylic material. We set the base angles of triangle rooftop at $35^{\circ}$ to advance high solar radiation transmissivity [9]. Figure 1 illustrates the structure of the greenhouse bunker in this experiment.

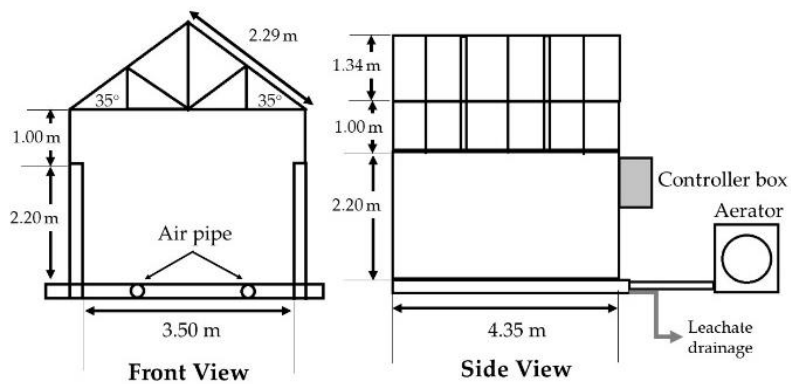

Figure 1: The structure of greenhouse bunker

\subsection{MSW preparation}

MSW feedstock from the On-nut waste transfer station in Bangkok, Thailand, was unpacked and mixed until homogenous. The feedstock was sampled to determine the initial characteristics prior to entering greenhouse bunkers. The MC measurement of MSW follows the oven-drying method at $105^{\circ} \mathrm{C}$ (ASTM D-3173, 1997), which employs a bomb calorimeter to estimate the heating value of MSW. Each greenhouse bunker loaded approximately $4,000 \mathrm{~kg}$ of MSW. The feedstock in all treatment units was set at $1.2 \mathrm{~m}$ height.

\subsection{Experimental design}

We performed three different conditions: a greenhouse with an aeration rate of $0.4 \mathrm{~m}^{3} /(\mathrm{kg}$. day) $(0.4 \mathrm{AR})$, a greenhouse with an aeration rate of $0.6 \mathrm{~m}^{3} /(\mathrm{kg} \cdot$ day) $(0.6 \mathrm{AR})$, and a passive aeration condition (CB). The $\mathrm{CB}$ was operated under a water-proof cladding, which is a non-greenhouse condition, to compare to the biodrying performance under the greenhouse condition. We assigned passive aeration in the control system, and this system was simulated as a conventional windrow biodrying. The experimental period of all conditions was 15 days.

\subsection{Data collection and monitoring}

In all greenhouse bunkers, four thermocouples were placed into the core layer of the MSW feedstock (more than $60 \mathrm{~cm}$ from the top of the waste pile) and on the waste pile surface. Meanwhile, one thermocouple was suspended above the waste pile inside the greenhouse, and another was set outside the greenhouse for measuring the ambient temperature. We used type $\mathrm{K}$ thermocouples with a temperature range of -270 to $1,327^{\circ} \mathrm{C}$ to monitor the temperature change during the experiment. A Graphtec (GL240, Japan) data logger recorded all temperature data. We installed a pyranometer (RK200-03, China) above the greenhouse to measure the solar radiation intensity, which crosses the greenhouses daily pending the experiment. The daily accumulated intensity values of solar radiation were retained by the data logger (RK600, China) connected directly to the pyranometer. Dried MSW at the $10^{\text {th }}$ and $15^{\text {th }}$ days was also sampled to determine the product characteristics during the drying process. Parameters and analytical methods are the same as those mentioned in section 2.2 .

\subsection{Assessment of drying performance}

All treatments in this experiment were compared based on various measurements of drying performance. We focused on weight loss, temperature differences, and the fraction of $\mathrm{HV}$ increase. Those indices are described as follows.

\subsubsection{Weight loss}

Weight loss is related to MC reduction after the drying process. We weighed the feedstock before and after the experiment to calculate the percentage weight loss $(\% w l)$ in different operating conditions using Equation 1. This index can indicate not only the mass reduction but also the fuel cost improvement for waste transportation.

$\% w l=(\Delta w / w i) \times 100$

where $\Delta w$ is the difference between initial and final MSW weights $(\mathrm{kg})$, and wi refers to the initial MSW weight $(\mathrm{kg})$. 


\subsubsection{Temperature difference}

An important parameter in bioprocessing is temperature, as it affects the biodegradation and evaporation of water in MSW. The daily temperature change during the experiment can indicate the drying behaviour in the system. The difference in operating conditions can result in heating moist MSW and, moreover, could affect the waste and ambient temperatures. To distinguish the temperature differences between the three treatments, the temperature integration (TI) indicates the accumulated daily differences between the average waste temperature and the ambient temperature. The calculation of $T I$ is as follows:

$T I=\sum_{i=1}^{n}(T W i-T A i)$

where $T W i\left({ }^{\circ} \mathrm{C}\right)$ refers to the average waste temperatures, and $T A i\left({ }^{\circ} \mathrm{C}\right)$ is the ambient temperature on the experimental day $i$. The different types of bunker coverages can cause variations in the air inside and outside the bunkers. The difference in air temperature $(D A)$, defined as the accumulated air temperature difference between inside and outside the treatments, indicates the effect of the different roof types. The calculation of $D A$ is shown below.

$D A=\sum_{i=1}^{n}(T G i-T A i)$

where $T G i\left({ }^{\circ} \mathrm{C}\right)$ refers to the air temperature in the system (or above the waste pile), and $T A i\left({ }^{\circ} \mathrm{C}\right)$ is the ambient temperature on the experimental day $i$.

\subsubsection{Heating value increase fraction}

The initial and final HVs were investigated, and the HV increase was reported in terms of an increasing fraction. The following equation shows the calculation of the fraction of $\mathrm{HV}$ $(H V F)$ increase:

$$
H V F=\Delta H V / H V i,
$$

where $\Delta H V$ is the difference between the final and initial $\mathrm{HVs}$, and $\mathrm{HVi}$ is initial $\mathrm{HV}$. The HV for this equation refers to the lower HV (kcal/kg).

\subsection{Statistical analysis}

The mean values of the hourly temperature at four monitored points in each MSW layer were reported. One-way analysis of variance was used to investigate the statistically significant differences between comparative treatments. To accept the alternative hypothesis that refers to a statistically significant difference between comparative treatments, a significance level of less than $5 \%(\mathrm{p}<0.05)$ was applied. The Pearson correlation was used to determine the correlation between the two parameters. The r-value refers to the correlation coefficient that describes the strength of the relationship between two variables in the positive or negative direction. The R program for windrows was used for all statistical analyses.

\section{Results and Discussion}

\subsection{Temperature profiles}

Typical aerobic decomposition is able to heat feedstock or organic substrates by microbial metabolism, which drives the temperatures above $50{ }^{\circ} \mathrm{C}$, and the organic degradation is performed by mesophilic and thermophilic microorganisms [10]. In this study, the pattern of temperature changes varies depending on operating conditions. A comparison of the temperature profile in different MSW layers is shown in Figure 2. The results show that $0.4 \mathrm{AR}$ achieved the highest temperature at the surface layer $\left(54.53 \pm 2.15^{\circ} \mathrm{C}\right.$ in daytime and $55.53 \pm 2.42{ }^{\circ} \mathrm{C}$ at night). Remarkably, there is a nonsignificant difference between surface temperatures in $\mathrm{CB}$ and 0.6AR on daytime $(\mathrm{p}=0.51)$ despite 0.6AR operating under the greenhouse condition. 0.6AR also presents the lowest average temperature at the surface MSW layer $\left(49.68 \pm 2.62{ }^{\circ} \mathrm{C}\right.$ in daytime and $47.22 \pm 2.37^{\circ} \mathrm{C}$ at night) because operating under $0.6 \mathrm{~m}^{3} /(\mathrm{kg}$. day) might release the heat inside the system by air ventilation.

As shown in Figure 2B, CB presents the highest core temperature $\left(54.69 \pm 2.92^{\circ} \mathrm{C}\right.$ in daytime and $54.39 \pm 2.60{ }^{\circ} \mathrm{C}$ at night) in comparison to the other treatments. It is evident that $\mathrm{CB}$ can hold the heat in the middle of the waste pile since there is no significant difference between the day and night core temperatures $(p=0.99)$. This result differs from the case of the greenhouse with the aeration system. In the 0.4AR and 0.6AR treatments, a significant difference occurred between the day and night core temperatures $(p<0.01)$. Additionally, there is a significant difference between core temperatures of 0.4AR and $0.6 \mathrm{AR}$ in the daytime $(\mathrm{p}<0.05)$, while the result shows no significant difference between them at night $(p=0.22)$. Remarkably, 0.6AR is the only treatment that shows a nonsignificant difference between surface and core temperatures $(p=0.22)$. Hence, the aeration rate influences the temperature profile of feedstock, which is an essential factor affecting the drying process in the system.

Figure $2 \mathrm{C}$ shows the air temperature inside the greenhouse among the treatments. There are significant differences in air temperatures in the system in the daytime between $\mathrm{CB}$ and $0.4 \mathrm{AR}$ $(\mathrm{p}<0.01)$ and between $\mathrm{CB}$ and 0.6AR $(\mathrm{p}<0.01)$. On the other hand, there is a nonsignificant difference in the air temperature between all treatments at night $(\mathrm{p}=0.99)$. The air temperature inside the greenhouse fluctuated extensively. These results indicate that solar radiation causes the air temperature to rise in the greenhouse condition. In the daytime, the difference in the air temperatures above the waste piles in $\mathrm{CB}$ and $0.4 \mathrm{AR}$ is $8.21^{\circ} \mathrm{C}$, while this difference is $8.75^{\circ} \mathrm{C}$ for $\mathrm{CB}$ and 0.6AR.

Temperature profiles illustrate the dissimilarity of temperature change patterns under various operating conditions. These profiles also show the critical role of aeration and greenhouse conditions in the biodrying process. Roble-Martinez et al. [11] conducted a study with laboratory-scale greenhouse dryers under passive aeration. The greenhouse in this study could perform drying temperatures between $23-32{ }^{\circ} \mathrm{C}$. Fabian et al. [7] conducted a similar study with artificial greenhouses under passive aeration, and the greenhouse achieved drying temperatures of $29-37^{\circ} \mathrm{C}$ within the first four days. Fabian et al. [7] stated that the waste temperature above $45^{\circ} \mathrm{C}$ for the thermophilic phase was unavailable owing to the low volume of the waste pile ( $0.5 \mathrm{~m}$ high and $2.5 \mathrm{~m}$ long), and the bio-heat was not sufficient to evaporate water in organic wastes in this case.

Meanwhile, the greenhouses of our study achieved a drying temperature range of $43.22-57.92^{\circ} \mathrm{C}$ in $0.4 \mathrm{AR}$ and $42.86-$ $52.49^{\circ} \mathrm{C}$ in $0.6 \mathrm{AR}$. The crucial factor was that the volume of the waste pile in our study was adequate for heat capture inside the MSW pile. For CB, the drying temperature range was $42.26-$ $56.94{ }^{\circ} \mathrm{C}$ similar to that of $0.4 \mathrm{AR}$. However, the obvious 
distinction is the air temperature in the bunker. The air temperature under the greenhouse condition was higher than in the non-greenhouse condition as $\mathrm{CB}$, and the higher air temperature indicates a higher water absorbability affecting the water content reduction.

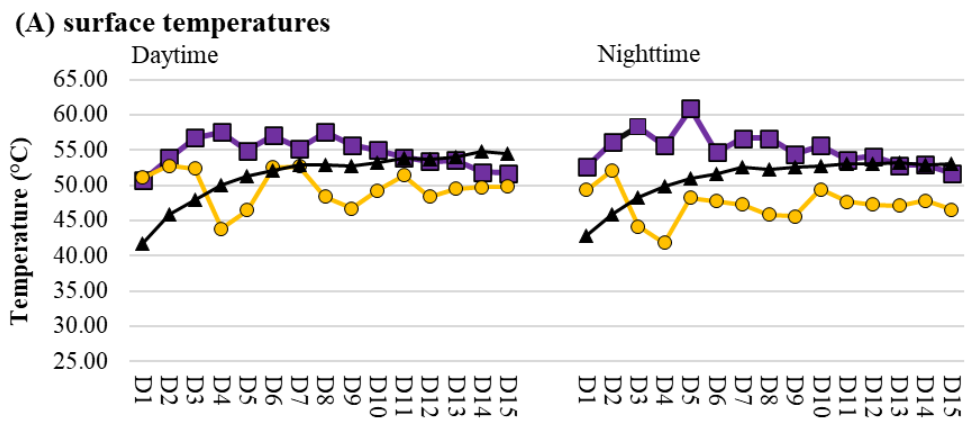

(B) core temperatures

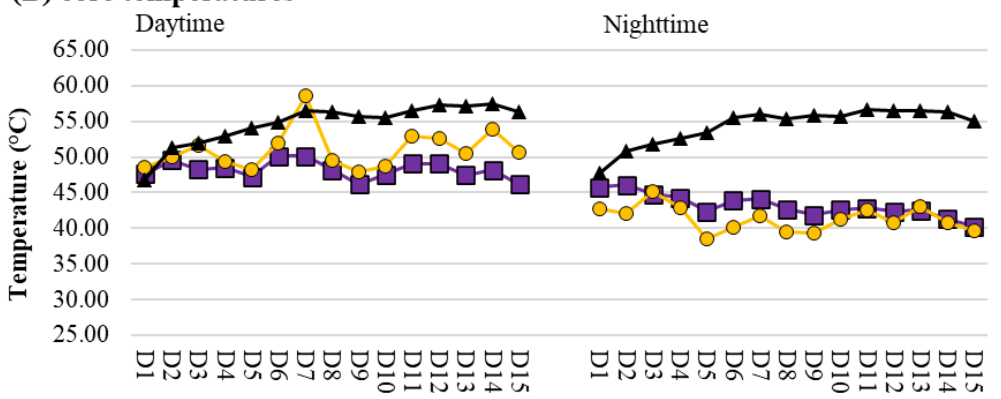

(C) air temperatures inside greenhouses

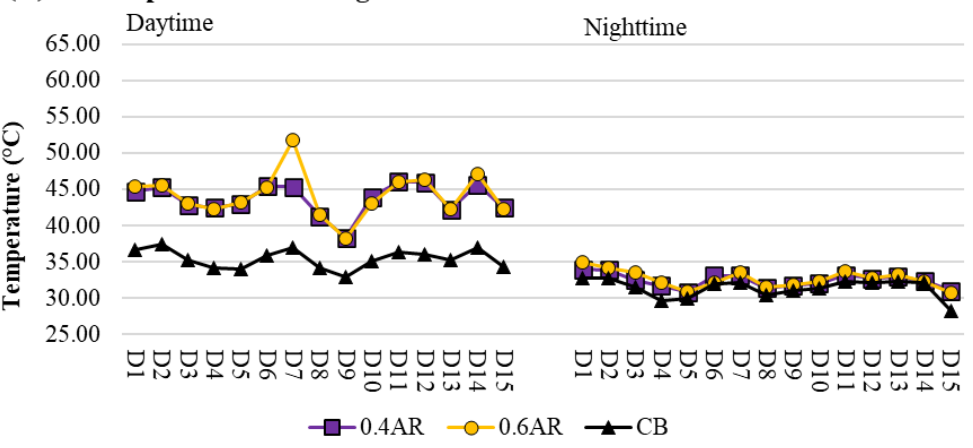

Figure 2: Temperature profiles of all treatments: surface temperatures, (B) core temperatures, and (C) air temperatures inside greenhouses

\subsection{Solar radiation intensity throughout the drying process}

Solar radiation is the determining factor in raising the air temperature inside greenhouse cladding. In this experiment, the minimum solar radiation was $8.34 \mathrm{MJ} /\left(\mathrm{m}^{2}\right.$. day $)$, and the maximum value was $17.70 \mathrm{MJ} /\left(\mathrm{m}^{2} \cdot\right.$ day $)$. The average value was $15.66 \mathrm{MJ} /\left(\mathrm{m}^{2}\right.$. day $)$. Figure 3 illustrates the relationship between solar radiation intensity and the air temperatures in the treatments. There are strong relationships between solar radiation intensity and air temperature inside the greenhouses in 0.4AR $(\mathrm{r}=0.76)$ and in 0.6AR $(\mathrm{r}=0.63)$. The result also shows a strong correlation between both parameters in the case of $\mathrm{CB}$, the non-greenhouse condition $(r=0.61)$. The correlation coefficients, or $r$-values, indicate that operating under the greenhouse condition with the low aeration rate $(0.4 \mathrm{AR})$ raises the air temperature in the greenhouse more significantly than the other cases. Meanwhile, 0.6AR can affect the air temperature inside the bunker when receiving solar energy as well as $\mathrm{CB}$. This result reveals the importance of airflow rate. Even though 0.6AR operated under the greenhouse condition, this airflow rate can be a disturbing factor that causes air temperature loss in the greenhouse. Nevertheless, there is no relationship between surface temperatures and solar radiation intensity

\subsection{Product characteristics}

The product from the drying process is RDF. According to the American Society for Testing and Materials (ASTM), RDF is classified into seven groups depending on physical characteristics. In this study, dried MSW is RDF-1 (in the form of raw MSW) following the ASTM standard E856-83 (2006) and requires an additional mechanical process to treat for $\mathrm{RDF}$ utilisation. Considering chemical characteristics, the desirable properties of RDF based on the market's needs are: 1) MC is less 
than $30 \%$ by mass, and 2) LHV is greater than $4,500 \mathrm{kcal} / \mathrm{kg}$ [12]. Table 1 shows the product characteristics in this experiment at the $10^{\text {th }}$ and $15^{\text {th }}$ days of the drying process. The result indicates that all treatment can reach an LHV of more than $4,500 \mathrm{kcal} / \mathrm{kg}$ within ten days. Nonetheless, the MC is still a significant concern for this experiment. The average MCs in the 0.6AR and $\mathrm{CB}$ cases were less than $30 \%$ within ten days. After 15 days, all treatments reached an average MC of less than $30 \%$. Remarkably, the high variability of both $\mathrm{MC}$ and $\mathrm{HV}$ occurred in this experiment because MSW as feedstock has high heterogeneity. Homogenising MSW and mixing during the drying process are recommended to achieve desirable $\mathrm{RDF}$ characteristics for the implementation on a commercial scale.

\subsection{Assessment of the biodrying process in the experiment}

This section addresses the assessment of biodrying process under different conditions. $T I$ and $D A$ were calculated following Equation 2 and 3, respectively. The accumulated temperature difference in the form of $T I$ indicates the self-heating capability under various conditions. Meanwhile, $D A$ can indicate the heat capture capacity in the bunkers. The result shows a significant difference of $T I$ between the treatments, and CB presents the highest $T I$ value (see Table 2).

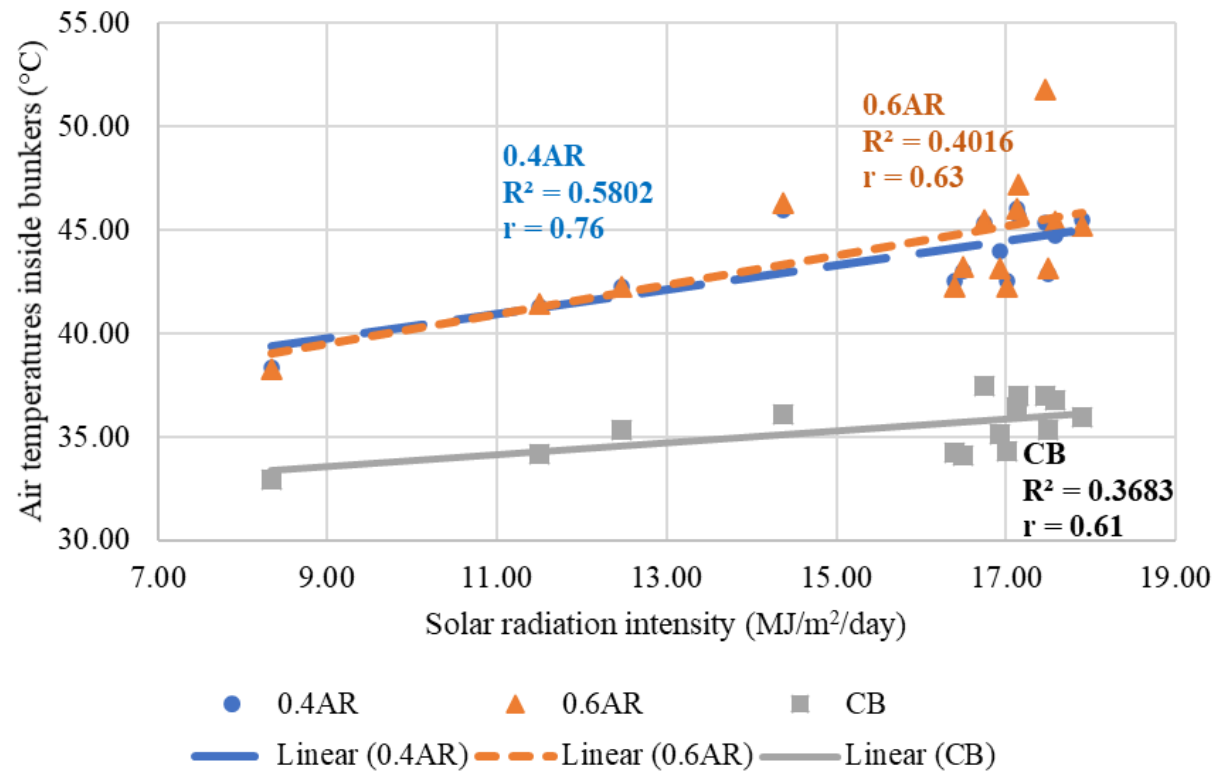

Figure 3: Relationship between solar radiation intensity and air temperatures in the bunkers

Table 1: Product characteristics

\begin{tabular}{|c|c|c|c|c|c|c|}
\hline \multirow[b]{2}{*}{ Treatment } & \multirow[b]{2}{*}{ Initial MC (\%) } & 10 days & 15 days & \multirow[b]{2}{*}{$\begin{array}{l}\text { Initial heating } \\
\text { value (kcal/kg) }\end{array}$} & \multirow{2}{*}{$\begin{array}{l}10 \text { days } \\
\begin{array}{l}\text { Final HV } \\
\text { (kcal/kg) }\end{array}\end{array}$} & \multirow{2}{*}{$\begin{array}{l}15 \text { days } \\
\begin{array}{l}\text { Final HV } \\
\text { (kcal/kg) }\end{array}\end{array}$} \\
\hline & & Final MC (\%) & Final MC (\%) & & & \\
\hline $\mathrm{CB}$ & & $26.24 \pm 12.85$ & $25.88 \pm 21.09$ & & $6,070.78 \pm 1,057.90$ & $6,461.63 \pm 1,006.95$ \\
\hline $0.4 \mathrm{AR}$ & $68.73 \pm 2.21$ & $33.62 \pm 18.49$ & $22.01 \pm 18.07$ & $901.44 \pm 270.65$ & $5,774.56 \pm 680.70$ & $7,550.84 \pm 265.55$ \\
\hline $0.6 \mathrm{AR}$ & & $24.62 \pm 10.08$ & $22.35 \pm 19.38$ & & $6,337.15 \pm 621.40$ & $7,079.80 \pm 17.55$ \\
\hline
\end{tabular}

Note: heating value refers to lower heating value (LHV) as received

Table 2: Assessment of biodrying between treatments

\begin{tabular}{llllllll}
\hline & \multirow{2}{*}{$\boldsymbol{T I}\left({ }^{\mathbf{C}} \mathbf{C}\right)$} & $\boldsymbol{D A}\left({ }^{\circ} \mathbf{C}\right)$ & Weight loss $(\boldsymbol{\%} \boldsymbol{w})$ & Moisture reduction & Moisture reduction & $\boldsymbol{H V F}$ & $\boldsymbol{H V F}$ \\
\cline { 5 - 8 } & & & & $\mathbf{1 0}$ days & $\mathbf{1 5}$ days & $\mathbf{1 0}$ days & $\mathbf{1 5}$ days \\
\hline $\mathbf{C B}$ & 607.11 & 23.75 & $21.26 \%$ & $61.82 \%$ & $62.35 \%$ & 5.73 & 6.17 \\
\hline $\mathbf{0 . 4 A R}$ & 529.66 & 163.03 & $24.82 \%$ & $51.08 \%$ & $67.98 \%$ & 5.41 & 7.38 \\
\hline $\mathbf{0 . 6 A R}$ & 439.91 & 173.92 & $28.84 \%$ & $64.18 \%$ & $67.48 \%$ & 5.29 \\
\hline
\end{tabular}


Remarkably, the aeration rate is inversely proportional to $T I$ $(r=-0.93)$, revealing the role of forced aeration on the heat capture in the MSW pile. Yuan et al. [13] conducted a study on the effects of bulking agent addition in biodrying process, and the aeration rate of their study was set at $0.43 \mathrm{~m}^{3} /\left(\mathrm{kg}_{\text {waste }}\right.$-day $)$. In the case of MSW feedstock, $T I$ was $523.7^{\circ} \mathrm{C}$, which is similar to the $T I$ in $0.4 \mathrm{AR}$ of our study. There is a nonsignificant difference in $D A$ between $0.4 \mathrm{AR}$ and $0.6 \mathrm{AR}(\mathrm{p}=0.72)$ despite operating under different aeration rates. This result indicates that the greenhouse condition has an effect on heat capture capability of air inside the system in comparison to the treatment with the non-greenhouse condition.

When considering weight and moisture reduction, weight loss is directly weakly proportional to moisture reduction $(\mathrm{r}=0.20)$. Unlike the meta-analysis study of biodrying from Tun and Juchelkova [2], this study found that the correlation coefficient between weight and moisture reduction was 0.80 in developing countries. This difference in results is due to the undefined MSW heterogeneity effect on the final MC in our study. However, the result shows a strong correlation between aeration rate and weight loss $(r=0.93)$ indicating the critical role of aeration in MSW weight reduction. $0.4 \mathrm{AR}$ had the least moisture decrease after ten days, but, by the $15^{\text {th }}$ day of the experiment, 0.4AR yielded the same $\mathrm{MC}$ as 0.6AR. Meanwhile, $\mathrm{CB}$ exhibited a constant moisture reduction rate in both the $10^{\text {th }}$ and $15^{\text {th }}$ days of the experiment. MC over $30 \%$ causes further bioactivity in the waste pile [14], so $0.4 \mathrm{AR}$ possibly continued bio-heat generation until the end of the biodrying process.

According to Table 2, the HV increased by more than five times in all treatments within ten days, and more than six times within 15 days of the drying process. Remarkably, the HV increase fraction increased by more than 1.5 from the $10^{\text {th }}$ to the $15^{\text {th }}$ day in the treatments under greenhouse condition with active aeration (0.4AR and 0.6AR). Meanwhile, this fraction increased by less than 0.5 times in CB.

Altogether, the results indicate that active aeration is vital for the biodrying process, and airflow rate affects the suitable drying time to obtain desirable RDF characteristics. Biodrying under the greenhouse condition with low active aeration can unlock the maximum efficiency of moisture reduction and $\mathrm{HV}$ increase in comparison to the control system of $\mathrm{CB}$, which has no significant change between 10 and 15 days of drying time. Although CB can reach the RDF standard of the market's needs within ten days, operating on the open condition has no sanitation on a waste management issue. In a study by Malinowski and Wolny-Koladka [15], the strains of pathogenic microorganisms, such as Staphylococcus aureus and Escherichia coli, were present in $\mathrm{RDF}$, which is a risk for developing illnesses. Hence, biodrying under the greenhouse condition could be a more hygienic option for waste treatment.

\section{Conclusion}

Biodrying under the greenhouse condition mainly helps to raise the air temperature inside the system through solar energy. However, the aeration system is an inevitable component in the biodrying process because the air movement plays a vital role in reducing MSW weight and MC. The aeration rate is of concern since it is related to the waste temperature and weight reduction in the drying process. Biodrying under the greenhouse condition with active aeration potentially has higher efficiency in $\mathrm{MC}$ reduction and $\mathrm{HV}$ increase compared to the non-greenhouse condition with passive aeration. 0.6AR and $\mathrm{CB}$ produced desirable characteristics of RDF based on the market's needs within ten days, while $0.4 \mathrm{AR}$ yielded this state after 15 days. Nevertheless, operation in the CB condition is not recommended because an open system is non-hygienic for waste management. The heterogeneity of MSW yielding uncertainty of RDF characteristics, especially in $\mathrm{MC}$, is a significant concern. Homogenising and mixing prior to the biodrying process should be added. However, the balance of energy consumption for the biodrying process with additional machinery required for desirable RDF characteristics should be further evaluated.

\section{Aknowledgment}

This research was financially supported by the Thailand Research Fund (TRF), Pairojsompongpanich Co. Ltd. (PSP), The Joint Graduate School of Energy and Environment (JGSEE), King Mongkut's University of Technology Thonburi (KMUTT), and the Center of Excellence on Energy Technology and Environment (CEE), PERDO, Ministry of Higher Education, Science, Research and Innovation. We extend our sincere thanks to Asst. Prof. Dr. Suthum Patumsawad and Assoc. Prof. Dr. Pipat Chaiwiwatworakul for their advice. Additionally, we most gratefully acknowledge all cohorts in the waste research team at JGSEE for their help to facilitate the experiment.

\section{Ethical issue}

Authors are aware of, and comply with, best practice in publication ethics specifically with regard to authorship (avoidance of guest authorship), dual submission, manipulation of figures, competing interests and compliance with policies on research ethics. Authors adhere to publication requirements that submitted work is original and has not been published elsewhere in any language.

\section{Competing interests}

The authors declare that there is no conflict of interest that would prejudice the impartiality of this scientific work.

\section{References}

1. MHESI. BGC in Action: The new sustainable growth engine: Ministry of Higher Education, Science, Research and Innovation; 2019 Available from: https://www3.rdi.ku.ac.th/wpcontents/uploads/2019/11/ข้ อ เ ส น อ - BCG-in-action_The-NewSustainable-Growth-Engine.pdf.

2. Tun MM, Juchelková D. Drying methods for municipal solid waste quality improvement in the developed and developing countries: A review. Environmental Engineering Research. 2018;24(4):529-42.

3. Shao L-M, He X, Yang N, Fang J-J, Lü F, He P-J. Biodrying of municipal solid waste under different ventilation modes: drying efficiency and aqueous pollution. Waste management \& research. 2012;30(12):1272-80.

4. Tom AP, Pawels R, Haridas A. Biodrying process: A sustainable technology for treatment of municipal solid waste with high moisture content. Waste management. 2016;49:64-72.

5. Dębicka M, Żygadło M, Latosińska J. The effectiveness of biodrying waste treatment in full scale reactor. Open chemistry. 2017;15(1):6774. 
6. DEDE. Total solar radiation intensity in Thailand: Department of Alternative Energy Development and Efficiency, Ministry of Energy; 2017 Available from: http://www.dede.go.th/ewt_news.php?nid=47941\&filename=solar_e nergy.

7. Fabián R-M, Elizabeth M, Teodoro E-S, Belem P, Carmen C-M, Francisco $\mathrm{J}$, et al. Biodrying under greenhouse conditions as pretreatment for horticultural waste. Journal of Environmental Protection. 2012;2012.

8. Zaman B, Oktiawan W, Hadiwidodo M, Sutrisno E, Purwono P. Calorific and greenhouse gas emission in municipal solid waste treatment using biodrying. Global Journal of Environmental Science and Management. 2020.

9. Castilla N. Greenhouse technology and management: Cabi; 2013.p. 78.

10. Antunes LP, Martins LF, Pereira RV, Thomas AM, Barbosa D, Lemos LN, et al. Microbial community structure and dynamics in thermophilic composting viewed through metagenomics and metatranscriptomics. Scientific reports. 2016;6:38915.

11. Colomer-Mendoza FJ, Robles-Martinez F, Herrera-Prats L, GallardoIzquierdo A, Bovea M. Biodrying as a biological process to diminish moisture in gardening and harvest wastes. Environment, development and sustainability. 2012;14(6):1013-26.

12. CNRE. The RDF report: the solution to waste management: Committee on Natural Resources and Environment, National Legislative Assembly; 2017 Available from: https://library2.parliament.go.th/giventake/content_nla2557/d11166 0-11.pdf.

13. Yuan J, Zhang D, Li Y, Chadwick D, Li G, Li Y, et al. Effects of adding bulking agents on biostabilization and drying of municipal solid waste. Waste management. 2017;62:52-60.

14. Diaz LF, De Bertoldi M, Bidlingmaier W. Compost science and technology: Elsevier; 2011. p. 57.

15. Malinowski M, Wolny-Koładka K. Investigation of the self-heating process of an alternative fuel derived from municipal solid waste. Proceedings of ECOpole. 2015;9(1):261-8. 